\title{
The Relevance of the Idea of "Community of Inquiry" to Contemporary Ethics. \\ In memory of Matthew Lipman (†2010)
}

\section{Roberto Franzini Tibaldeo (Pisa)}

\author{
Matthew Lipman and the Community of philosophical Inquiry
}

Problematic and complex aspects of democratic life ? such as the teaching of the concept of civil liberties, more about the spreading of responsible participation and pluralistic dialogue, the mutual understanding of different cultures and individuals, and the fulfilment of a common civil life based upon shared rules, procedures, and reasonable dialogue ? are not yet solved and certainly need to be frequently revisited and reviewed. I believe that Matthew Lipman?s reflection on philosophical community practice, although developed in the 1970s, is still relevant to our contemporary age. Although Lipman developed the idea of ?Philosophy for Children? (P4C) and ?Community of Inquiry? within the school context, and although he did not aim to immediately extend it to society as such, I think that there are very interesting reasons which can support this possibility. The present essay will precisely try to put them in evidence.

Who was Matthew Lipman (1922-2010)?? Unfortunately, I was not so lucky to know him personally. So, in order to answer to the previous question, I would like to report an indirect biographical fragment. A friend of mine, Antonio Cosentino ? who introduced Lipman?s ?Philosophy for Children? in Italy at the beginning of the Nineties3 ? once told me how he had met Matthew Lipman. It happened during a meeting in Graz (Austria) at the end of the Eighties. At that time, Antonio was a school teacher seeking for new ways of teaching philosophy. He was quite unsatisfied of the didactical method used in Italian high schools and based on Western philosophy as a theoretical science only. So his curiosity was aroused by Lipman?s curriculum and by the seminar which was to be held in Graz. The meeting commenced with a session of $\mathrm{P} 4 \mathrm{C}$, and this already impressed Antonio. What is more, everyone knew that Lipman was a participant in the community, but no one was able to recognize him. Only after the session was concluded Lipman introduced himself.

This anecdote reveals a very important aspect of that philosophical practice called ?Philosophy for Children?, namely its capacity of creating a democratic setting for mutual respect. This is, indeed, a fundamental prerequisite for the enhancement of individual freedom and for the accomplishment of the social aims. Democracy, however, has itself a precondition ? and that is what I find so interesting in Antonio?s story: it requires you to acquire a critical and self-critical view of yourself, to temporarily step back from yourself and your beliefs, to initially put into brackets the role you play in society.

What leads Lipman to these reflections? His philosophical and pedagogical research begins with a negative experience: while teaching philosophy to college students and adult education students in the Sixties, he notices that they generally have great problems with thinking critically, inquiring about philosophical questions and forming reasonable judgments. Lipman lays the blame for this situation on traditional education: the greatest disappointment of traditional education consists in its failure in generating persons who draw near to the ideal of reasonableness (Lipman, 1985). What is, indeed, evident and problematic is the fact that traditional education has no efficacy in the spreading and consolidation among citizens of civil virtues (Lipman, 2003).

Beginning with theoretical premises close to pragmatism and to constructivism, but also acquiring ideas from contemporary continental hermeneutics and from the epistemology of complexity4, Lipman aims to go beyond the current idea of an educational system, in search of a new philosophical and pedagogical paradigm so as to comprehend the overall formation of the individual?s dispositions and main features of the democratic citizen.

Education and democracy can in no way be separated5. This is a debt Lipman incurs directly from Dewey, who devoted important essays to this theme (see, for instance, Dewey, 1916). Like Dewey, Lipman believes that the democratic context is both the indispensable premise and the never sufficiently gained goal for a renewed education system, the aim of which is to stimulate the spread of reflective, autonomous, and critical thinking 6 . Moreover, the aim is to give rise to dialogue, selfcorrection, and inquiry, in order to eliminate the forces which cause violence, ignorance, and injustice 2 . Democracy is, according to Lipman, the space and the political environment where human relations take place. Two fundamental aspects are fulfilled by a democratic context: on the one hand, an aptitude to research distinguished by fallibility and self-criticism, and, on the other hand, the recognition of the value assigned to procedures and their respect by citizens.

This outline is, however, incomplete without an indication of the extent to which philosophy plays a relevant role. Lipman refers again to Dewey, when he says, ?Our society could not be fully civilized and our schools could not be fully satisfactory [...] until students were converted to inquiry and thereby prepared to be participants in a society likewise committed to inquiry as the sovereign method of dealing with its problems? (Lipman, 2003, p. 34). 
It is well-known that Dewey interprets ?inquiry? as ?scientific inquiry?․ Lipman, on the other hand, understands the idea of ?philosophical inquiry? in a wider sense, by referring to an idea of philosophy as a philosophical practice, and not as an exercise of theoretical and abstract knowledge only. In keeping with this, Lipman defines inquiry as perseverance in self-corrective inquiry regarding relevant and problematic questions (Lipman, 1985). It is, however, important to notice that such a philosophical practice may take place in a community only with others who share the same desire to participate in a philosophical inquiry.

A ?Community of Inquiry? (CI), therefore, begins with this shared desire. Moreover, participants ought also to share the ?commitment to reasonableness ? that is, to rationality tempered by judgement? (Lipman, 2003, p. 111) and to reciprocally recognize the need for a collective sharing. The heart and vehicle of expression of this inquiry is, according to

Lipman, philosophical dialogue, which differs from conversation, debate, and mere communication (Lipman, 2003, pp. 87-93). Philosophical dialogue is certainly argumentative and ?critical?, but at the same time it also evidences ?creative? and ?caring? dimensions9. Lipman synthesizes the specific characteristics of a CI in this way: ?Every community of inquiry has about it a requiredness or Prägnanz that lends it a sense of direction, and every participant in such a community partakes of that qualitative presence, which is the tertiary quality of which Dewey speaks. It is a quality more readily possessed than described, but were it not present and acknowledged, the participants would lack any standard of relevance or irrelevance? (Lipman, 2003, p. 86).

Therefore, not every community is a community of philosophical inquiry, least of all because of the fact that to be such a community there have to be acknowledged and shared commitments, norms, procedures, and responsibilities. Later on in this essay, I shall try to draw out from these characteristics, the ethical relevance of the philosophical inquiry shared by a community.

However, in order to identify the effects produced on an individual taking part in a CI, Lipman points out some fundamental characteristics leading to the full achievement of a reasonable (and, therefore, democratic) person and citizen. Among these individual and social competences we find the following: autonomy, reflectivity, self-reflectivity, self-correction, sensitivity to context, ability to use critical and self-critical thinking, as well as creative and caring thinking, competence to argue and to sustain the reasons of personal choices, actions and beliefs (Lipman, 2003, pp. 25-27).

\section{Community of Inquiry and ethical reflection}

Any CI is closely connected to questions about the sense of individual and social values. This happens because of the ?caring? thinking (that is, it being value-oriented), which together with the logical-critical and the creative thinking involved makes a person (and a collective discussion) able to put into practice a ?higher-order thinking? (Lipman, 1995, p. 1). As already mentioned, it is precisely the so called Prägnanz ${ }^{10}$, which ? according to Lipman ? marks the difference between communities in which a philosophical inquiry process takes place from the ones where this does not occur. Prägnanz endows the community and its members with a parameter ? gained through the common inquiry ? by which they are able to evaluate what is relevant and to distinguish it from what is not. Lastly, the philosophical inquiry deriving from a collective commitment is, as such, already oriented to action and, therefore, to ethics. This is possible because, according to the pragmatist roots of Lipman?s reflection, any philosophical inquiry deals with problems arising from praxis, and with the reasonable expectation of being able to synthesize them into a higher-order thinking or solution.

Another ethically relevant aspect concerns the relationship between the individual and the community, and subsequently between individual values and shared values. Experience says that the answer to these issues lies theoretically within a range of solutions displayed between two extremities, which actually happen to be typical pathologies of our globalized epoch: on the one hand, there is the defence of the irreducibility of the individual, while, on the other hand, there is the nullification of the individual in favour of a new and amplified communitarian subject, which ? therefore ? seems to assume its own substantiality and individuality (Pulcini, 2009; Honneth, 1994).

Lipman avoids both extremities. From one aspect, Lipman states that there is a certain priority set by the world and the social environment upon individuality (because of a first movement proceeding from the social towards the individual)프. However, for another, Lipman never forgets to point out that the relation between an individual and a community displays a dialectics of freedom. This dialectics, as explained by Lipman, avoids the annihilation of the individual freedom in the community situation, but, at the same time it shows how any individual is-placed-inside a specific and historical context, into ? expressed as contemporary hermeneutics ? a horizon of pre-comprehension as the fundamental condition of possibilities for any human relation. Moreover, Lipman rejects the transformation of a community into a substantial and autonomous entity, while stating, at the same time, that the community is also characterized by a form of ulteriority. This means that a community, being more than the sum of its individuals, represents a certain reserve of possibilities and sense for its members. In addition, he insists that the plexus of individual freedom and responsibility can never come to a conscious and critical or self-critical realization if separated from a tangible social context. Lipman, however, does not deny the freedom of individuals, or to remove the responsibility for individual behaviour. 
As regards explicitly ethical issues, Lipman points out their relation to the two above-mentioned characteristics identifying practical reasoning: self-correction and sensitivity to context. Moreover, any ethical issue must be placed alongside other (ethically relevant) characteristics of human reasoning, such as the intrinsically normative feature of ?caring thinking? (thanks to which it is possible to compare being with ought-to-being) 12 , or the predictive feature, which characterizes rationality as such. In fact, to comprehend something implies being able to single out its relations with the conditions and reasons producing it and with the effects deriving from it ${ }^{13}$. The derivation of this idea from American pragmatism is evident.

Indeed, the ethical relevance portraying human reason finds its match in the ethical colouring of the CI. These two dimensions inevitably reflect one another dynamically: on the one hand, the collective inquiry appears to be relevant for individual ethics (because of the active, motivated, and responsible participation of its members), while, on the other hand, thanks to its relational and social core, the subject always ponders, evaluates, and acts within a dialogical and social context. Since ? at least theoretically ? in a CI the single members are encouraged to widen their ethical positions, it can certainly be said that as such a CI shows a certain relevance for public ethics.

In what sense does this occur? Firstly, a CI is interested in discussing fundamental questions of sense. Secondly, its community research is based on theoretical statements, such as the following: pluralism of values and of Weltanschauungen; the possible conflict between them; the fact that the different options displayed may not be able to face each other rationally in order to achieve a fair and reasonable solution, together with their general aim (the attempt to handle existing pluralism); and, finally, the choice in favour of a democratic procedure of rational confrontation.

However, an additional word has to be spent on the meaning of ?democratic procedure? for a CI. This concept is not only connected to ? as we usually assume ? a mainly logical-argumentative confrontation, a politics controlling and orienting pluralism, or the mediation of private and public interests. Moreover, according to Lipman, the CI?s ?democratic procedure? highlights a precise commitment, that is to undertake a broad research involving the whole thinking project. To some extent, such procedure is something into which each member is at a stake with his/her values in order to come to a productive result. It is like a filter which opens the possibility for mediation or, finally, a practice of mutual recognition ${ }^{14}$, self-regulation and formation aiming to responsibly assume a certain choice.

However, what difference is there between a decision-oriented discussion and a CI research? Indeed, it has to be said that the democratic method practically adopted by a CI seems to consist in a filter opening the possibility for higher-order mediation. The aim of a CI is not immediately and exclusively the search for agreement or the decision-making process, but the philosophical inquiry as such. In this respect, a CI definitely differs from a case of discourse or communication ethics.

\section{Community of Inquiry and responsibility}

On the other hand, in what specific sense is a community of philosophical inquiry actually committed to taking a decision and producing a practical result? How can we completely understand Lipman?s following words, according to which a CI is ?a process that aims at producing a product? at some kind of settlement or judgement, however partial and tentative this may be? (Lipman, 2003, p. 83)?

In light of what has already been said, it should be clear that this result is a product of common knowledge, that is, a cooperative construction of sense and a process of negotiation to which each member of the community takes part (Striano, 2005, p. 56-58). Because of its intrinsically philosophical character (that is, fallible, revisable, and self-corrective), this product ought to be continuously and dialogically discussed. The inquiry product? being a ?kind of settlement or judgement? (Lipman, 2003, p. 83) ? appears to be the result of a ?deliberation?, a concept which Lipman defines as follows: ?This involves a consideration of alternatives through examination of the reasons supporting each alternative. Since the deliberation usually takes place in preparation for the making of a judgement, we speak of the process as a ?weighing? of the reasons and the alternatives? (Lipman, 2003, p. 96).

Hence, the inquiry produced by a community appears to steer clear of the effective fulfilment of specific actions and decisions. The determination and planning of these seems, indeed, not to be in primis the aim of the inquiry. As evidenced at the end of the previous paragraph, the philosophical inquiry refers to a different logic from the one driving problem solving strategies, whose aim is to discuss a specific question with the sole idea of coming to a specific deliberation for final practical application 15 . In order to solve a problematic situation (as previously mentioned, this aim is implicit in the same idea of ?inquiry?), collective inquiry certainly takes off from singular circumstances and specific problems. Yet, as such, the process of philosophical reflection always preserves a sort of ulteriority with respect to this situation. It does, in fact, characterize the peculiarity of philosophical inquiry and of its method, according to which, in order to face a problem, it is first necessary to widen its context and horizon, which then makes it possible to examine deeply all philosophical devices (terms, ideas, interpretative keys, etc.) previously used. As a consequence, the initial problem is examined in a new light and in a renewed context of sense. For this reason, I believe that the ?deliberation? (that is the product of common thinking) may be followed by some kind of practical modification in the life of the community and of its members $\frac{16}{}$. 
In what sense, however, can the practical relevance of philosophical community inquiry be detected and understood? In what sense does it generate a practical modification in the life of the community and of its members? I believe these questions may find a form of clarification through a meditation on the ethical-philosophical idea of responsibility. Its significance is testified to by the fact that the concept of responsibility is able to consider both the effective consequences of human behaviour and the wider and challenging horizon of sense, within which actions and consequences happen (Jonas, 1979; Rothstein, 2008; Nussbaum, 2010). In other words, I believe that, thanks to an interpretation of the community pragmatics in light of the ethics of responsibility, it is possible to obtain important results: first, an overall interpretation of the sense of human action can be reached; second, the consequences of actions can be considered; third, how the reflective praxis of a CI can generate positive effects for the social praxis.

In order to show the appropriateness of this hypothesis, I have to briefly highlight the main features and the possible outcomes of a CI discussion. First, the community decides to create a constructive atmosphere and manage a dialogue according to a certain procedure (namely, the one that characterizes a CI). This decision is based on the preliminary and free assent of the community members. Furthermore, this assent is joined to a freely assumed commitment to adhere to the procedure. Second, from these fundamental issues derive practical consequences, such as the fact that from now on people ?suspend? their ordinary social roles, that the discussion of selected topics will be characterized by a certain ?philosophical? style, and this will take place according to specific rules. Third, in cases where the experiment succeeds, it is reasonable to assume that certain consequences will follow. For example, it is highly probable that the participants receive an overall benefit in terms of personal reflective awareness. It is also probable that this awareness will increase if it finds further opportunities to be practiced (reinforcement effect). It is also probable that the acquired method of inquiry and the consequent increase of reflective awareness find further application to other topics some of which would have been previously unknown or unexpected. Fourth, it is likely that the growth of reflective skills within the CI and its members generates the improvement of other skills, such as the ability to evaluate questions, cooperatively imagining possible solutions, imagining alternative scenarios, predicting their possible consequences and effects on praxis, and monitoring the effective fulfilment of assumed decisions. Finally, from the effective achievement of the $\mathrm{CI}$, it is legitimate to expect that its members receive from this experience an increased incentive in terms of personal motivation to realize further collective inquiry.

Hence, the community philosophical discussion seems to reveal some advantages. First: it presents itself as a specific inquiry itinerary, which is, however, placed in a wider horizon of sense. For this reason, the inquiry is able to testify to fundamental characteristics of this overall sense, such as its complexity, relational essence, and practical constitution. Other specific issues revealed by this philosophical investigation are, in summary: free acceptance of a specific procedure, participation of the individuals, commitment to inquiry, construction and negotiation of meanings, recognition of other beings, sensitivity to value rationality, recognition of the emancipative power of community philosophical practice, and so on프. Second: the community discussion may outline an initial exemplification of the dynamics linking reflective praxis with social praxis, Reflection-inaction with instrumental-strategical action (Schön, 1983), and the collective inquiry/deliberation with the fulfilment of specific choices. Moreover, the experiment points out the heuristic process by which the $\mathrm{CI}$ and the ethics of responsibility can come to a reciprocal elucidation: on the one hand, the ethics of responsibility may display a coherent and unitary interpretation of the practical-philosophical dynamics of CI, while, on the other hand, the CI may lead to an understanding of the multiple levels of responsibility.

The first result of this reciprocal elucidation is the fundamental connection between the ideas of freedom and responsibility; the one requires the other. Indeed, personal freedom comes to self-realization only with the freedom of others, and according to the reciprocal relation of call-answer (that is of responsibility) 18 shown towards others. This means that before finding individual and specific fulfilment, freedom and responsibility are mutually implied as co-freedom and co-responsibility. In this respect, freedom and responsibility reveal a first fundamental level of meaning, consisting in an overall horizon of sense, of possibility, and of existence as such. On the one hand, the freedom and responsibility of the individuals and the community inquiry process find a consequent space and existence within this fundamental horizon. On the other hand, this horizon is liable to a process of continuous re-acceptance and re-configuration achieved by the freedom and responsibility of the individuals and of the CI.

However, a second element appears when a person chooses, intentionally, to take part in a CI ? the free choice coincides with the responsible acceptance of a limit, which opens a ?public? space for inquiry and existenceㄹ․ This freely accepted responsibility may find the following articulation: the individual is responsible a) for his own actions, and for their consequences, b) towards the other members of the community (responsibility as ?care?), c) towards the community inquiry process (epistemic responsibility) (Striano, 2005, p. 51), d) for the philosophical quality of the results of the collective inquiry, e) for the possible effects deriving from the practical fulfilment of specific decisions taken at a collective level.

\section{Conclusions}

In this essay I tried to argue that Lipman?s paradigm of ?Philosophy for Children? as a ?Community of Inquiry? is very useful in extending the benefits of philosophical community reflection to collective life as such. I have not focussed on the question of whether Lipman?s paradigm is the best for this purpose, and I acknowledge that further research would be necessary in order to reach such a conclusion²0. Instead, I have tried to develop the above mentioned aim in order to discuss the possible contribution of philosophy to the ethical and political dynamics which, nowadays, seem to characterize many relational and deliberative 
public contexts. In doing this, I have tried to apply to these contexts the interpretative key supplied by Lipman?s CI. Subsequently, I attempted to interpret a CI essentially in terms of an ethics of responsibility which is committed to two aims: on the one hand, to give a unitary and improved picture of the plexus of freedom and responsibility, and, on the other hand, to reinterpret fundamental philosophical issues, such as the emancipative power of philosophical practice for the individual, the fact that philosophy ought to inquire about the reasons for participation in democracy, and the role that this reflective practice may play in the individual and community existence. I believe that the future debate on these topics will greatly benefit from Lipman?s reflection. Indeed, this is the greatest gift he could leave us before departing.

\section{References}

Casarin, P. (2005). Valenze formative e potenzialit? emancipative delle pratiche filosofiche. In: Cosentino, 2005a, pp. 104-122.

Cosentino, A. (ed.) (2002). Filosofia e formazione. 10 anni di Philosophy for Children in Italia(1991-2001). Napoli: Liguori.

Cosentino, A. (2004). Effetti emancipativi della comunit? di ricerca. Pratiche filosofiche (2, 1), pp. 45-50.

Cosentino, A. (ed.) (2005a). Pratica filosofica e professionalit? riflessiva. Napoli: Liguori.

Cosentino, A. (2005b). Teoria e pratica nella formazione dei docenti. Il modello della ?P4C?. In: Santi, 2005, pp. 63-80.

Cosentino, A. (2005c). La pratica del filosofare per lo sviluppo di una professionalit? riflessiva. In: Cosentino, 2005a, pp. 9-45.

Dewey, J. (1916). Democracy and Education: an Introduction to the Philosophy of Education. New York: Macmillan.

Dewey, J. (1933). How we think. Boston: Heat.

Dewey, J. (1938). Logic: the Theory of Inquiry. New York: Holt, Rinehart and Winston.

Franzini Tibaldeo, R. (2011). Un?idea di responsabilit?. L?etica jonasiana e le sue prospettive. Turin: PhD diss., University of Turin.

Fraser, N.-Honneth, A. (2003). Redistribution or Recognition? A Political-Philosophical Exchange. London-New York: Verso.

Honneth, A. (1992). Kampf um Anerkennung. Zur moralischen Grammatik sozialer Konflikte. Frankfurt am Main: Suhrkamp.

Honneth, A. (1994). Pathologien des Sozialen. Die Aufgabe der Sozialphilosophie. Frankfurt am Main: Fischer.

Jonas, H. (1979). Das Prinzip Verantwortung. Versuch einer Ethik für die technologische Zivilisation. Frankfurt am Main: Insel. Eng. tr. The Imperative of Responsibility. In Search of an Ethics for the Technological Age. Chicago: University of Chicago Press, 1984.

Lipman, M. (1985). Philosophical practice and educational reform. Journal of Thought (20, 4), pp. 20-36.

Lipman, M. (1995). Caring as Thinking. Inquiry: Critical Thinking Across the Disciplines (15, 1), pp. 1-13.

Lipman, M. (2003). Thinking in Education (second edition). Cambridge: Cambridge University Press.

Lipman, M. (2008). A Life Teaching Thinking. An Autobiography. Montclair (NJ): Institute for the Advancement of the Philosophy for Children.

Lipman, M.-Sharp, A. M. (1978). Some educational presuppositions of Philosophy for Children. Oxford Review of Education (4, 1), pp. 40-58.

Martens, E. (1999). Philosophieren mit Kindern. Eine Einführung in die Philosophie. Stuttgart: Reclam.

Morin, E. (1973). Le paradigme perdu: la nature humain. Paris: Seuil.

Morin, E. (1991). Introduction ? la pensée complexe. Paris: ESF.

Nussbaum, M. C. (2010). Not for Profit. Why Democracy Needs the Humanities. Princeton: Princeton University Press.

Peirce, C. S. (1935-58). The Fixation of Belief. In: Id., Collected Papers. Cambridge, Harvard University Press. 
Pulcini, E. (2009). La cura del mondo. Paura e responsabilit? nell?et? globale. Torino: Bollati Boringhieri.

Rothstein, R. (2008). Grading Education: Getting Accountability Right. Washington (D.C.): Economic Policy Institute.

Santi, M. (ed.) (2005). Philosophy for Children: un curricolo per imparare a pensare. Napoli: Liguori.

Schön, D. A. (1983). The Reflective Practitioner. New York: Basic Books.

Striano, M. (2002). Insegnare a pensare. Un?esperienza di formazione a pensare il pensiero. In: Cosentino, 2002, pp. 137-147.

Striano M.-Oliverio S. (ed.) (2007). A. M. Sharp. ?Philosophy for Children?, un percorso educativo attraverso la filosofia. Iride (20, 51), pp. 249-269.

Taylor, Ch. (1992). Multiculturalism and ?the Politics of Recognition?. An Essay. Princeton: Princeton University Press.

Vygotskij, L. S. (1934). Thought and Language. Cambridge (Mass.): The Mit Press, 1986.

Roberto Franzini Tibaldeo (roberto.franzinitibaldeo@sssup.it) is Research Fellow in Political Philosophy at the Sant?Anna School for Advanced Studies (Pisa) and ?Cultore della Materia? (Scientific Expert) in Moral Philosophy at the University of Turin. He holds a Ph.D. in Science of culture (2005) and a Ph.D. in Philosophy (2011). Among his research interests: contemporary nihilism, philosophy of technology, philosophy of biology, political and ethical implications of the idea of responsibility, philosophy of education, landscape and environmental ethics, intercultural studies, philosophy for community.

1. See, for instance, the following statement by M. Lipman: ?And if reasonableness prevails in the classroom today, then tomorrow, when today?s students are adults and beginning to have children of their own, it will also prevail in the home. In time, other institutions may be transformed in a similar fashion, but it must all begin in the schools? (Lipman, 2003, p. 123) (context)

2. Further biographical notes may be found on the following website (http://www.nytimes.com/2011/01/15/education/15lipman.html) and in M. Lipman?s autobiography (Lipman 2008). (context)

3. See Cosentino, 2002; Cosentino, 2005a; Cosentino, 2005b. (context)

4. See Morin, 1973; Morin, 1991; Lipman, 2003; Cosentino, 2002; Cosentino, 2005a. (context)

5. On this topic, see for instance Nussbaum, 2010. (context)

6. For the notion of ?reflective thinking?, see Dewey, 1933; Schön, 1983; Lipman, 2003. (context)

7. For the relation between democracy and reduction of violence, see Lipman, 2003, pp. $105 \mathrm{ff}$. (context)

8. See Dewey, 1933; Dewey, 1938; Peirce, 1935-58; Lipman, 2003, p. 20; Striano, 2002, pp. 139 ff. (context)

9. For the articulation of human rationality according to Lipman, see Lipman, 1995 and Lipman, 2003. (context)

10. With Prägnanz Lipman refers to the capacity of a CI to distinguish what is relevant and what has a value for the collective discussion (Lipman, 2003, p. 86). (context)

11. This movement explains the development of the individual?s rationality and shows how reflection originates from dialogue (Lipman, 2003). In this respect, Lipman?s thinking appears to be evidently influenced by L. Vygotskij (Vygotskij, 1934). (context)

12. See Lipman, 2003, pp. 34-35. (context)

13. See Striano-Oliverio, 2007, p. 259; Cosentino, 2002a. (context)

14. For the relevance of the notion of individual and social recognition, see Taylor, 1992; Honneth, 1992; Fraser-Honneth, 2003; Pulcini, 2009. (context)

15. According to A. Cosentino, the philosophical dialogue which occurs in a CI is ?a kind of knowledge which does not correspond to the level of instrumental knowledge (acquiring of information, computing of data, problem solving). On the contrary, it has mainly to do with horizons of sense, values, cognitive paradigms, ways of interpreting reality, global attitudes towards experience? (Cosentino, 2005c, p. 42). See also Lipman, 2003, p. 26. (context)

16. Therefore, a kind of ?utility? can be expected from a CI: ?community of inquiry?, says Cosentino, ?assigns the logical products of the inquiry in order to restore its overall order and to improve the conditions of existence and of everyday life? (Cosentino, 2005c, p. 29). Indeed, this evidences a second meaning of the word ?deliberation?, that is its ?what for? and its aim of a practical fulfilment. In this sense, a deliberation is something which has to respond for the possible consequences deriving from its realization. (context)

17. See, for instance, Cosentino, 2004; Casarin, 2005; Rothstein, 2008; Nussbaum, 2010. (context)

18. The word ?responsibility? derives from the Latin respond?re and responsum dare, which imply the idea of being committed to giving an answer to someone to some extent. Also the German word meaning ?responsibility?, namely Verantwortung, has conserved this responsive meaning (Antwort = answer). Franzini Tibaldeo, 2011, pp. 59. (context)

19. See above, for the productive tension/friction of human relationships. (context)

20. For a critical analysis of different methods of philosophizing with and for children, see Martens, 1999. (context) 
